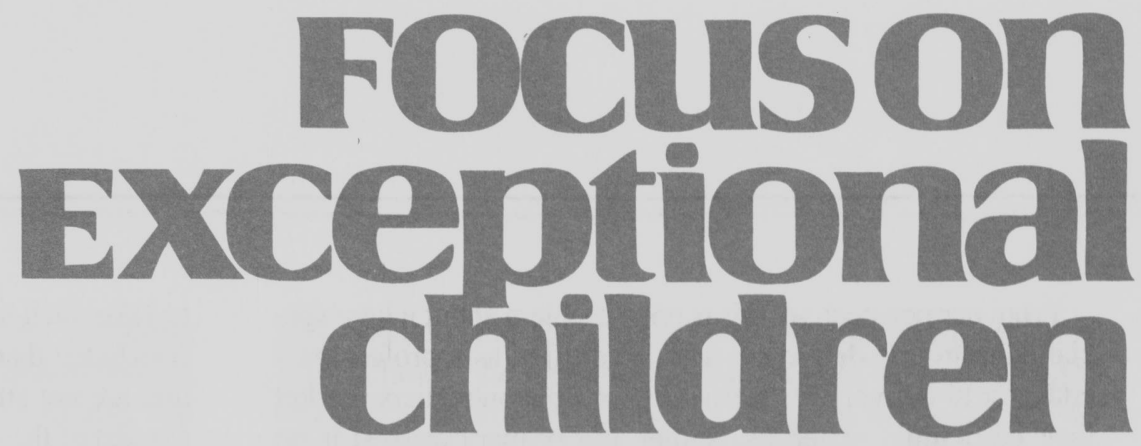

\title{
A Focus on Curriculum Design: When Children Fail
}

\section{Deborah C. Simmons and Edward J. Kameenui}

In a preview to the "Reading Report Card," U. S. Department of Education Secretary Richard Riley profiled recent national scores indicating that only one-third of high school seniors read proficiently ("Reading Scores," 1995, p. A7). In addition, approximately 75\% of fourth and eighth graders scored below the proficient range - which represents a significant decline in reading performance from previous years. A conspicuous finding revealed that, while scores for the top quarter of students remained stable from previous years, the most significant decline involved children at the bottom of the achievement scale.

General and special educators can easily assign faces and names to the children profiled in the national statistics. Some we know as students with specific learning disabilities and language disorders; others are considered at-risk for reading failure, and still others may have no identified disability, yet have consistently struggled throughout their academic careers to keep up with their age-level peers. Though varieties of nomenclature are used to identify these children and many characteristics used to describe their behaviors, their common denominator is failure (Kameenui, 1993). More specifically, they are failing to achieve from traditional curriculum and instruction.

This article is devoted broadly to the topic of academic failure, and specifically to the role of curriculum design in either intercepting or exacerbating learning difficulties. A focus on curriculum design does not discount the fact that learners in the bottom of the achievement rankings may differ along biological, neurological, experiential, sociological, and psychological dimensions from those who rank consistently near the top. Rather, this emphasis acknowledges the real differences these learners bring to instruction and to the body of knowledge and science of instruction professional educators possess to address these needs.

The emphasis on curriculum design shifts the focus from factors over which teachers have little control (e.g., neurology) to those that are amenable and capable of preventing and remediating failure. Our goals in this article are to (a) provide a demographic and instructional context for the need to attend to curriculum design at both a national and a local level, (b) define and specify the dimensions of curriculum design, (c) apply curriculum design principles to select academic contents, and (d) discuss implications of poorly designed instruction for students with diverse learning needs.

Deborah C. Simmons and Edward J. Kameenui are affiliated with the Division of Learning and Instructional Leadership at the University of Oregon College of Education.

C Love Publishing Company, 1996 
From our perspective, this is not a problem about where special education is delivered, who is certified as a professional educator to deliver the instruction, or how publishers market their curriculum materials. Rather, our primary interest is on the features of instructional tools, how they are implemented, and their effect on children with diverse learning needs.

\section{WHY CHILDREN FAIL: THE DEMOGRAPHIC/INSTRUCTIONAL CONTEXT OF GENERAL EDUCATION}

The heart of scientific inquiry rests in the search for and discovery of causes. It is human nature to ask why, and when children fail, the areas to indict and investigate are seemingly infinite. In 1992, Phi Delta Kappa published a study of students at risk entitled, Growing up Is Risky Business and Schools Are Not to Blame. The authors reported researchers' reluctance to pin down causes, because specifying causation implies personal responsibility and "researchers are hesitant

\section{FOCuson Exceptional children}

ISSN 0015-511X

FOCUS ON EXCEPTIONAL CHILDREN (USPS 203-360) is published monthly except June, July, and August as a service to teachers, special educators, curriculum specialists, administrators, and those concerned with the special education of exceptional children. This publication is annotated and indexed by the ERIC Clearinghouse on Handicapped and Gifted Children for publication in the monthly Current Index to Journals in Education (CIJE) and the quarterly index, Exceptional Children Education Resources (ECER). The full text of Focus on Exceptional Children is also available in the electronic versions of the Education Index. It is also available in microfilm from Xerox University Microfilms, Ann Arbor, MI. Subscription rates: Individual, \$30 per year; institutions, $\$ 40$ per year. Copyright (C) 1996, Love Publishing Company. All rights reserved. Reproduction in whole or part without written permission is prohibited. Printed in the United States of America. Second class postage is paid at Denver, Colorado. POSTMASTER: Send address changes to:

Love Publishing Company

Executive and Editorial Office

P.O. Box 22353

Denver, Colorado 80222

Telephone (303) 757-2579
Edward L. Meyen

University of Kansas

University of Kansas Medical Center to take such steps" (Frymier et al., 1992, p. v). The report concluded that children's problems, including academic failure, are not attributable to schools but instead to the broader context of the culture in which they live. Precisely, society, in which schools are a part, is responsible, and to understand children's failure, we must address the larger context of society. If society is to blame, the following statistics confirm that general and special education have an ominous task ahead.

\section{Changing Demography and Increasing Complexity}

Today, many more students bring linguistic, experiential, cognitive, and sociological differences to school that require more of teachers and the instructional curriculum. The following data from the Sixteenth Annual Report to Congress substantiate this increasing trend. In 1992-93, more than five million children birth through age 21 received services under Part B of the Individuals with Disabilities Act (IDEA) and Chapter I of the Elementary and Secondary Education Act-an increase of $3.7 \%$ from the previous year. The change in total number of children served from the previous year parallels recent trends of 2 to 3 percent increases per year since 1988-89. Approximately half of these students were classified as having learning disabilities and received much of their instruction in general education (U. S. Department of Education, 1994).

More children with disabilities and diverse learning needs are being educated in general education than ever before (Fuchs \& Fuchs, 1994; McLeskey \& Pacchiano, 1994). Estimates of the range of instructional levels within general education already are high, with more than five grade levels represented per classroom in some schools (Jenkins, Jewell, Leceister, Jenkins, \& Troutner as cited in Fuchs \& Fuchs, 1994). In general, teachers and classrooms in general education are not prepared to address the learning and curricular needs that children bring to classrooms (Baker \& Zigmond, 1990). Observational and self-report data indicate that the type and quantity of instructional adaptations in general education are insufficient to effect "optimal growth" for many low-performing students in general education (Zigmond et al., 1995).

The portrait of the typical American classroom is changing dramatically. Some of the changes indicate that a growing number of students, including those with disabilities, may not acquire basic, fundamental academic skills and strategies. Perhaps never before have the demographics of an individual classroom presented such complex and diverse demands on teachers and the curricula. Those responsible for addressing the unique and varying needs of learners may find the complexity unwieldy in the face of growing class sizes and reduced instructional support. 
These conclusions highlight that classrooms are becoming more complex and traditional curriculum and instruction are unlikely to address students' diverse needs. Recognizing that children's academic failure is a complex challenge undoubtedly complicated by social problems, poverty, deteriorating family structures, and so forth, we are compelled to examine the role of schools and the role of curriculum design in understanding why children do not profit from unspecialized or general instruction. In this article, we describe how instructional tools, when designed properly, can mediate the learning demands and difficulties of students with disabilities and other students with diverse learning needs.

\section{Curriculum Design: A National Concern}

The educational imperative is clear, though the focal point is obscured by the myriad of factors that influence learning. Mosenthal (1982) proposed that models of learning (and failure) can never be specified fully. More likely, a search for causation and intervention will focus on "partial specifications" of factors most proximal and amenable to change.

More than three decades ago, Carroll (1963) suggested that student learning was based on (a) characteristics of the learner, (b) the time devoted to learning an objective, and (c) the quality of instruction. In addressing learning problems, to assert that educators tend to focus primarily on the learner is fair even though variables within the learner are the most resistant to change because they are unobserved, private, and entirely outside teachers' influence. The second factor, time devoted to learning, is limited by the number of hours in a school day, as well as the range of objectives and activities in the curriculum. Although efficiencies can be achieved to make instructional time more effective, instructional time is often a fixed variable.

More important, diverse learners and children with disabilities

constantly face the tyranny of time in trying to catch up with their peers, who continue to advance in their literacy development. Simply keeping pace with their peers amounts to losing more and more ground for students who are behind. (Kameenui, 1993, p. 379, emphasis added)

Playing "catch up" in school requires using time and every learning opportunity judiciously, strategically, and preciously. Moreover, playing catch-up exacts an enormous cost on students, teachers, administrators, and parents, and the gains are not likely to occur unless the pedagogical machinery is precisely tuned, performance-based, instruction- ally oriented, and almost free of instructional and curricular error. Finally, the opportunities for these students to advance or catch up diminish greatly over time, and the cognitive and emotional fatigue in trying to catch up is also high. Given the extraordinary challenges inherent in playing catch-up, the best strategy is not to get behind in the first place; to intervene early, frequently, and purposefully to get ahead and stay ahead.

The final factor, quality of instruction, has the greatest potential to affect the needs of students with diverse learning needs. Quality of instruction is influenced by the quality of instructional tools available to teachers and the quality of instructional techniques used to deliver the instruction.

Interestingly, the quality of instruction component of Carroll's (1963) model is central to the concept of "special education" and is implicated, albeit indirectly, in the federal statutory definition of special education. Specifically, special education is defined in the Individuals with Disabilities Education Act (IDEA) (20 USC 1401 et seq.) as specially designed instruction, at no cost to parents, to meet the unique needs of a child with a disability (Bateman, in press). Citing this statutory definition is much easier than interpreting what it means, which, according to Bateman's (in press) most recent legal analysis, is akin to untying the Gordian knot with one hand restricted.

Although the legal interpretation of what "specially designed instruction ... to meet the unique needs of a child with a disability" means is beyond the scope of this article, suffice it to say that the instructional program must be "reasonably calculated" to allow the child to benefit. The standard for gauging whether a child benefits is determined on a case-bycase basis and influenced substantially by many factors (e.g., documented lack of progress under alternative instructional conditions, controlling legal precedent, current state laws, suitable balance between goals of academic progress and least restrictive environment).

The legal and statutory complexities in determining what passes for quality instruction notwithstanding, some special educators have called for reforming special education by relying on instructional and educational tools and curricular programs with the "strongest support in theory and reliable empirical research" (Kauffman, 1994, p. 616). In other words, quality instruction should be determined not by what is popular, but by what is tested, evaluated, and proven to be effective for all students, especially diverse learners (Carnine, 1993; Worrall \& Carnine, 1994). As Kauffman (1994) implored in his recent call for reforming special education, "Special education carries special responsibility for care in teaching or it has no meaning, regardless of where or by whom it is offered" (p. 616-617). 


\section{RESPONDING TO FAILURE: THE ROLE OF EDUCATIONAL TOOLS}

For several decades researchers have investigated the relation of curriculum design and instruction to learner outcomes. Findings from studies in content areas ranging from history to vocabulary learning to mathematics indicate a class of variables that consistently and positively affect academic performance for children with diverse learning needs. The primary source that defines instruction in classrooms is the published curriculum and, specifically, textbooks.

The role of textbooks as the main vehicles of information is well documented (Armbruster \& Ostertag, 1993; Baker \& Zigmond, 1990; Hoffman et al., 1994). In reading, more than 90 percent of classroom instruction is based on commercial educational materials and, specifically, the basal reader (Komoski, cited in Kameenui, 1993). Mayer, Sims, and Tajika (1995) have noted that textbooks actually may serve the role as a "national curriculum" (p. 456) because of their widescale adoption and influence.

Observational and student achievement data indicate that the type and quantity of instruction based on basal programs and traditional adaptations are insufficient to effect optimal or even satisfactory growth for many students with learning disabilities (Baker \& Zigmond, 1990). In a study of kindergarten through fifth-grade reading instruction, Baker and Zigmond found that instruction was taught "by the book," largely undifferentiated, and conducted in large groups. Inclusion of students with increasingly diverse learning needs, reliance on a predominant instructional tool, and modest to limited instructional adaptations in general education seemingly call for a ratcheting up of the overall quality of conventional instruction. For example, one strategy for improving instruction is to enhance the quality of the "tools" most commonly used as the base of reading instruction.

\section{Improving the Quality of Instructional Tools: A National Agenda}

The diverse and changing demography of today's classrooms places increasing responsibility on developers and publishers to produce educational tools that effect positive change in all learners. Recognizing the widespread use of published curricula and their impact on students with diverse learning characteristics, the Office of Special Education Programs (OSEP) of the U. S. Department of Education announced a series of research priorities to investigate the quality of instructional tools. The first of these cooperative agreements was awarded to the University of Oregon in 1991, with a specific emphasis on improving the quality of instruction tools for students with diverse learning needs. The National Center to Im- prove the Tools of Educators (NCITE) was established at the University of Oregon, College of Education, in September, 1991, and is directed by Douglas Carnine and Edward Kameenui. Kauffman (1994) has recognized the work of NCITE in his call for special education reform.

NCITE's position is that quality tools that effect positive change in all learners can be identified and advanced by relying on scientifically derived knowledge based on methodologically sound research. Holding to these criteria, NCITE is conducting comprehensive analyses of research on the characteristics of students with diverse learning needs, field testing educational tools in authentic contexts, and soliciting feedback from users of educational tools (e.g., teachers, developers, and publishers) to construct a scientific knowledge base. Three interdependent goals frame NCITE's strategy to improve the quality of educational tools:

1. To establish an empirical knowledge base that articulates the relation between attributes of quality technology, media, and materials and increased attainment of various valued outcomes for students with diverse learning needs

2. To advance the knowledge of publishers, developers, and the education marketplace about the attributes of quality educational tools

3. To increase awareness and support for the use of highquality educational tools.

NCITE's mission is to increase awareness and promote the use of high-quality educational tools by providing publishers and developers information about the attributes of quality education tools. These attributes have been derived from research on curriculum design variables and the field testing and analyses of educational tools. NCITE has conducted extensive research syntheses in the academic areas of mathematics, beginning reading (e.g., phonological awareness, emergent literacy, word recognition), text structure, language arts (e.g., integrating reading and writing), social studies, and science.

Based on these research syntheses, NCITE has identified six generic principles that traverse a range of academic content areas and are sufficiently encompassing, sensitive, and flexible to capture the distinct and critical features of varying academic domains and cognitive constructs (e.g., phonological awareness, metacognition). The six principles include big ideas, conspicuous strategies, mediated scaffolding, strategic integration, judicious review, and primed background knowledge. These curriculum design principles provide a framework for examining and fortifying instruction in ways that improve the overall quality of instruction and mediate some of the difficulties that students with disabilities encounter. 


\section{Defining Curriculum Design}

Curriculum design refers to the way information in a particular domain (e.g., social studies, science, reading, mathematics) is selected, prioritized, sequenced, organized, and scheduled for instruction within a highly orchestrated series of lessons and materials that make up a course of study. Curriculum design provides a broader context for instructional design, which, according to Smith and Ragan (1993), refers to the "systematic process of translating principles of learning and instruction into plans for instructional materials and activities" (p. 2). As Smith and Ragan pointed out:

\section{An instructional designer is somewhat like an engi- neer-both plan their works based on principles that have been successful in the past-the engineer on the laws of physics, and the designer on basic principles of instruction and learning. (p. 2)}

Whereas the engineer, to extend Smith and Ragan's analogy, is concerned with developing the architectural, electrical, and mechanical plans for building physical structures, the instructional designer is concerned with developing the architectural pedagogy for the communication of symbolic information that has a high probability of preventing learner errors and misconceptions and misrules (Tennyson \& Christensen, 1986). Primarily because instructional design is concerned with the communication of symbolic information mediated by a learner, however, it is difficult to appreciate fully what curriculum design looks like, how it fits a particular instructional situation, whether it works for all learners or just some, or how it is related directly to student performance.

Perhaps an important feature of curriculum design is that it is concerned with the intricacies of analyzing, selecting, prioritizing, sequencing, and scheduling the communication of information before it is packaged for delivery or implemented. It is the behind-the-scenes activity that appears as the sequence of objectives, schedule of tasks, components of instructional strategies, amount and kind of review, number of examples, extent of teacher direction, and support explicated in teachers' guides and lesson plans. Curriculum design is the blueprint for instruction that carries significant potential for students with diverse learning needs.

Some blueprints are skeletal, providing little instructional specification, and others have fundamental flaws that fail to provide an adequate foundation on which to build further skills and future learning success. For example, consider the following modified directions illustrative of a current commercial reading program:

Have children look at the illustration and name the pets in the picture. Elicit the word pig and write it on the board. Tell children they will learn about the sound

\begin{abstract}
they hear at the beginning of pig and the letter that stands for that sound. Ask children to read the first line of the poem. Have them find the word pig and match it with the word on the board. Then, as you read the words, ask children to tell which word in the pair begins with the same beginning sound as pig.
\end{abstract}

This excerpt may seem a benign exercise in beginning reading. Nevertheless, for children at-risk for reading failure, with language delays, or with identified reading disabilities, this activity and those of comparable instructional design can exact pervasive and negative consequential effects on longterm academic development. Because this is an excerpt from a larger reading lesson, we cannot evaluate the lesson fully and perhaps fairly. Select features, however, may complicate learning unintentionally and in a sense promote failure.

We will discuss specifics of curriculum design in subsequent sections. Suffice it to say, though, that the activity makes far too many assumptions about learner preskills, promotes inefficient and ineffective strategies, and relegates teaching to assessment. Moreover, if individuals have not been prepared to evaluate curriculum from a design perspective, the more subtle design problems of the activity may go unnoticed although the effects on learners are likely to be evident in their inability to perform the associated tasks.

If this example is representative of contemporary curricula, and given the importance of curriculum design in preempting learning problems, how does one go about evaluating curriculum systematically and sufficiently? What criteria do you use to evaluate curriculum to determine whether the instructional tool is likely to structure information in ways that are memorable, manageable, and meaningful for students with diverse learning needs? To answer these questions, we recommend the six principles NCITE uses as minimum criteria for evaluating curricula. Carnine (1994) noted that these criteria are not fully specified. Rather, they are offered in the spirit of initiating a dialogue about how educators can make instructional decisions for students who have diverse learning needs. They do not represent a definitive guide to developing, selecting, or modifying curricula but, instead, a starting point for evaluating and selecting instructional tools.

\section{PRINCIPLES OF EFFECTIVE CURRICULUM DESIGN}

\section{Big Ideas}

Big ideas are concepts and principles that facilitate the most efficient and broadest acquisition of knowledge across a range of examples in a domain (Carnine, 1994). Big ideas enable students to learn the most and learn it as efficiently as 
possible by serving as anchoring concepts by which "small" ideas often can be understood. For students with diverse learning needs, these conceptual anchors are becoming more important in this age of information proliferation.

The growing amount of information to be learned is a source of heavy pressure on educators. In their book, Curriculum for a New Millennium, Longstreet and Shane (1993) estimated that by the late 1990 s, the quantity of available information will double every 24 months. In effect, this means that learners in today's schools will be exposed to more information in a year than their grandparents were in a lifetime. For students who have difficulty acquiring and maintaining information, a focus on big ideas seems pivotal to manage the amount of information in textbooks.

The tendency of American education to expose students to concepts and information is not new and, unfortunately, not restricted to a particular subject area. In 1989 Porter discussed the consequences of curricula that teach for exposure, and the impending compromises on depth of understanding. An article in Education Week (1994) also profiled the tendency of United States textbooks to emphasize breadth over depth.

\begin{abstract}
We cover lots and lots of things, more than anybody else in the world, but we don't do anything in great depth. ... Science textbooks in the United States typically are two to four times longer than those in other countries .... and yet it's just those constant snippets of information. While some countries expect 13 year olds to cover 10 to 15 scientific topics in depth, U.S. textbooks rush them through 30 or 40 topics. (p. 10)
\end{abstract}

How publishers select, prioritize, and connect information is a design issue, and one that warrants serious consideration of big ideas. The major assumptions of big ideas are that (a) not all curriculum objectives and related instructional activities contribute equally to academic development, and (b) more important information should be taught more thoroughly than less important information (Carnine, 1994). Although some information is fundamental to a domain, other ideas are simply not essential, particularly for students with diverse learning needs who face the tyranny of time and must catch up with their peers. For these learners, in particular, big ideas have to be prominent features of instructional tools in the respective content areas. Big ideas should be the instructional anchors of programs for students with diverse learning needs. This does not suggest other information should not be taught, simply that it should not have equal weight or equal time.

\section{Conspicuous Strategies}

Strategies are a general set of steps that students follow to solve problems. Many students induce the steps in a strategy on their own. Inducing learning strategies, however, may require a considerable amount of time before the student identifies the optimum strategy. For students with diverse learning needs, this approach is highly problematic because instructional time is a precious commodity and these learners may not induce an effective or efficient strategy. Learning is most efficient when strategies are made explicit. In addition, strategies are most effective when they are of medium breadth and can be generalized.

When applied to a process such as reading comprehension and a specific skill such as determining the main idea, a conspicuous strategy is the set of steps that leads to effective and efficient comprehension and identification of the main idea. Unfortunately, many students with diverse learning needs do not intuit or figure out that the main idea tells about the whole paragraph or story until much time has passed and many opportunities for learning have been exhausted. Moreover, published curricula may not provide the strategic steps necessary for teachers to communicate the process adequately.

Teachers, then, must make explicit the steps proficient readers use to determine whether the main idea is stated explicitly or implicitly, discriminate most important from less important information, summarize ideas, and come to a reasonable conclusion. If educational tools do not provide these steps explicitly either in teacher directions or in printed examples, the burden rests on the teacher to devise and communicate these strategies.

\section{Mediated Scaffolding}

Mediated scaffolding refers to the personal guidance, assistance, and support that a teacher, peer, materials, or task provides a learner. It should be seen as temporary support to assist during initial learning. On new or difficult tasks, scaffolding may be substantial and then removed systematically as learners acquire knowledge and skills. Scaffolding can be accomplished through multiple formats including the careful selection of examples that progress from less difficult to more difficult, the purposeful separation of highly similar and potentially confusing facts and concepts (e.g., /p/ and /b/ in early letter-sound correspondence learning), the strategic sequencing of tasks that require learners to recognize then produce a response, or the additional information that selected examples provide, such as highlighting the digits used in a division problem.

American texts are qualitatively different from the instructional tools of other nations in the types of scaffolded examples. Specifically, Mayer, Sims, and Tajika (1995) compared American and Japanese textbooks in teaching mathematical problem solving. They commented, "Japanese textbooks con- 
tained many more worked-out examples ... than did the U. S. books." One of the primary conclusions was the Japanese textbooks tend to support learners in the learning process by providing multiple examples of successful problem solving strategies, whereas "in the U.S., textbooks are more likely to provide lots of exercises for students to solve on their own without much guidance" (p. 457). This type of guidance seems critical for students with diverse learning needs.

Finally, scaffolding is not a static, predetermined instructional condition. Rather, the degree of scaffolding covaries with the learner's abilities, the goals of instruction, and the complexities of the task. Educators must determine the level and degree of scaffolding necessary. Nonetheless, the extent to which published curricular materials build in support structures will facilitate teachers' ability to provide the scaffolding that learners need.

\section{Strategic Integration}

Strategic integration involves the careful combination of new information with what the learner already knows to produce a more general, higher-order skill. Integrating new information with existing knowledge increases the likelihood that information will be understood at a deeper level. The integration must be strategic so new information does not become confused with what the learner knows already. Likewise, it must be parsimonious, emphasizing critical connections.

For new information to be understood and applied, it should be integrated with what a learner knows and understands already. For example, narrative composition seems to invite a logical sequence for integrating story grammar elements strategically across reading comprehension and written composition based on identification, application, and generation activities. In beginning reading, once learners can hear sounds in words and recognize letter-sound correspondences, those skills can be integrated to recognize words. These powerful and often logical connections comprise strategic integration.

\section{Judicious Review}

Successful learning also depends on a review process to reinforce the essential building blocks of information within a content domain. According to Dempster (1991), the pedagogical jingle of "practice makes perfect" is not a reliable standard to ensure successful learning. Simple repetition of information will not ensure efficient learning.

Dixon, Carnine, and Kameenui (1992) identified four critical dimensions of judicious review:

1. Sufficient to enable a student to perform the task without hesitation
2. Distributed over time

3. Cumulative with information integrated into more complex tasks

4. Varied to illustrate the wide application of a student's understanding of the information.

So how does a teacher select information for review, schedule review to ensure retention, and design activities to extend a learner's understanding of the skills, concepts, or strategies?

According to Dempster (1991), "spaced repetitions," in which a learner is asked to recall a learning experience, are more effective than "massed repetitions," if the "spacing between occurrences is relatively short" (p. 73). As early as 1917, Edwards (cited in Dempster, 1991) observed that elementary school children who studied academic information once for 4 minutes and again for $2 \frac{1}{2}$ minutes several days later retained about 30 percent more information than students receiving one continuous $61 / 2$ minute session. Repeated presentations of shorter time increments distributed over time, therefore, should be considered when scheduling instruction.

\section{Primed Background Knowledge}

Successful acquisition of new information depends largely on (a) the knowledge the learner brings to a task, (b) the accuracy of that information, and (c) the extent to which the learner accesses and uses that information. For students who have diverse learning needs, priming background knowledge is critical to success, as it addresses the memory and strategy deficits they bring to tasks. In effect, priming is a brief reminder or prompt that alerts the learner to task dimensions or to retrieve known information.

For example, if learners are facile in hearing and manipulating sounds in words and can identify letter-sound correspondences reliably, they are prepared to learn how to apply that information to identify words. Students with diverse learning needs, however, may not access information in memory as efficiently and effectively or may not rely consistently on effective strategies to identify unknown words. In these cases, the task of priming background knowledge is paramount to subsequent reading success.

A minimum of three guidelines should be considered when priming background knowledge:

1. Identify essential preskills or background knowledge most proximal to the new task

2. Once proximal tasks are identified, determine whether the background knowledge needs to be primed or taught

3. Provide the priming necessary to elicit the correct information or ready the learner by focusing attention on a difficult task or component of a task. 


\section{Summary of Curriculum Design Principles}

These six instructional principles serve as the primary guidelines for designing tools to promote learning for students with diverse learning needs (see Table 1). All too often, tools for most students do not consider the unique characteristics and needs of an increasing number of students who demand higher quality instruction (e.g., Kameenui \& Simmons, 1990).

As expectations for students increase, accountability for achievement also increases. As classrooms become more complex environments and the needs of learners more diverse, teachers must rely on effective instructional tools, based on quality curriculum design principles, to increase the likelihood that students will attain and maintain information successfully. In the next section, we illustrate the application of curriculum design principles to selected content areas.

\section{APPLICATION OF CURRICULUM DESIGN PRINCIPLES TO HISTORY, MATHEMATICS, BEGINNING READING, AND WRITING}

The six principles serve as the minimum pedagogical framework for design of a curriculum for all learners, especially students with diverse learning and curricular needs. De-

\section{TABLE 1 SUMmary of CRITICAL DIMENSIONS OF CURRICULUM DESIGN PRINCIPLES}

Principle Criteria/Features
Big Idea: Concepts, principles, or heuristics that facilitate the most efficient and broad acquisition of knowledge
1. Focus on essential learning outcomes
2. Capture rich relationships learning
Conspicuous Strategies:
Useful steps for accom-
1. Planned
2. Purposeful
plishing a goal or task
3. Explicit
4. Of medium-level application
5. Most important in initial teaching

3. Enable learners to apply what they learn in varied situations

4. Involve ideas, concepts, principles, and rules central and fundamental to higher-order

5. Form the basis for generalization and expansion
Mediated Scaffolding: Instructional guidance
1. Varied according to learner need and experiences provided by teachers,
2. Based on task (not more than learner needs)
peers, materials, or tasks
3. Provided in the form of tasks, content, and materials
4. Weaned or removed according to learner proficiency
Strategic Integration: Integrating knowledge as
a means of promoting higher-level cognition
1. Combines cognitive components
2. Results in a new and more complex knowledge structure
3. Aligns naturally with information (i.e., not "forced")
4. Involves meaningful relationships
5. Links essential big ideas across lessons within a curriculum
Primed Background Knowledge: Preexisting information that affects
1. Aligns with learner knowledge and expertise
2. Considers strategic and proximal preskills
3. Readies learner for successful performance new learning

\begin{tabular}{ll}
\hline Judicious Review: Struc- & 1. Sufficient \\
tured opportunities to & 2. Varied \\
recall or apply informa- & 3. Distributed \\
tion previously taught & 4. Cumulative \\
& 5. Judicious
\end{tabular}


veloping a pedagogical framework around these six principles is an enormously complex task that involves expert knowledge of a domain (e.g., earth science, geometry) and expertise in instructional design for diverse learners. We do not expect classroom practitioners or curriculum development specialists to have all this knowledge. Nor do we expect teachers to design curriculum materials from scratch or redesign and modify existing curricula in substantial ways. The following applications of the six principles in the areas of history, mathematics, reading, and writing exemplify curriculum design that is both possible and necessary for the full range of learners.

As Smith and Ragan (1993) noted, selecting what to teach (e.g., the big ideas in a specific domain) and specifying the intricate requirements of when (e.g., strategic integration, judicious review) and how (e.g., conspicuous strategies, mediated scaffolding, primed background knowledge) to teach is akin to pedagogical engineering. This engineering is predicated on the presumption that a fundamentally sound curriculum design increases the probability that the information will be communicated to all learners successfully. Although the big ideas across the various domains are necessarily different, the principles for how and when to teach those ideas share a procedural sameness; that is, understanding mediated scaffolding and judicious review in the context of teaching phonological awareness in beginning reading, should facilitate the understanding of mediated scaffolding and judicious review in the context of teaching concepts in other content areas including history, mathematics, writing, etc. In the following examples, we illustrate the covariation of curriculum design principles and content.

\section{History}

Big ideas can be critical in content areas such as social studies, history, and science. Expository or content area texts typically are complicated if not unmanageable for students with diverse learning needs. Although a number of factors, including density of information, text structure, and vocabulary, contribute to their difficulty, a large problem is the manner in which information is presented as lists of facts instead of strategies that promote general knowledge (Gehrke, Knapp, \& Sirotnik, 1992, cited in Nolet \& Tindal, 1994). History texts and instruction frequently are criticized as being a chronological sequence of events learned primarily by memorizing names, dates, and places (Brophy, 1990; Kinder \& Bursuck, 1991). In general, history texts introduce far too much information and make far too few explicit connections (Carnine, Miller, Bean, \& Zigmond, 1994). Beck, McKeown, and Gromoll (1989) found that textbook content did a poor job of helping students understand the underlying principles that account for historical events. Thus, the responsibility re- sides with the teacher or learner to make connections (a) between events, (b) between what is being learned to what has been learned previously, and (c) between what is being learned and what will be learned next.

An alternative presentation of history is a structure that emphasizes the relations and sameness between important events. For example, a big idea in history is a problem-solution-effect model that can provide a widely general strategy for understanding historical events and their interrelatedness (Carnine, Miller, et al., 1994). In this strategy, learners recognize a structure or sameness that underlies most historical problems. Specifically, "common problems in history can be attributed to (a) economic or (b) human rights issues" (Carnine, Miller, et al., 1994, p. 434).

Solutions to historical problems likewise can be classified into one of five types: moving, inventing, dominating, accommodating, or tolerating. Attempts to solve problems produce consequences or effects that frequently lead to other problems, reinforcing the relations between the parts. When instructional tools design information around such relational linkages, teachers' responsibilities can shift from designing to delivering information in ways that engage, involve, and motivate learners. Concomitantly, well-designed lessons that make content connections explicit further enhance the likelihood that students will relate historical events within the given period of time and also to more contemporary problems.

For example, U. S. history is filled with examples of individuals who, in the face of economic and human rights problems in their native countries, solved their problems by moving to a new country (Carnine, Miller, et al. 1994). The effect of moving eliminated the economic or human rights problems of some people. For others, moving resulted in new economic or human rights problems, which sometimes were more severe than the initial problem.

The colonists' flight from English rule is one example of a group of individuals who moved in an attempt to solve the problem of government control and the conflict between church and state. But the Tories' attempt to dominate through taxation created an even larger problem, escalating into a more severe form of domination: war. In relation to current events, parallel problems exist throughout the world, involving both economic (tariffs on imported automobiles) and human rights (e.g., Apartheid, Bosnia) issues. Through the problem-solution-effect model, these relations are made explicit, increasing the likelihood that students will retain the information.

Big ideas by themselves are important but insufficient and must be complemented with other effective design principles. For instance, in the problem-solution-effect model of history, conspicuous strategies are used to teach two general classes of problems (economic, human rights), five cate- 
gories of solutions, (moving, inventing, dominating, accommodating, or tolerating) and three categories of effects (the problem ends, the problem continues, or a new problem is caused by the solution).

Scaffolding can be used to assist students in completing a problem-solution-effect outline. Teachers first might identify the problem, solution, and effect, gradually relinquishing the responsibility as students become proficient. This gradual transfer of responsibility to the learner is likely to increase (a) academic success, because students are given greater assistance early when they most need it, and (b) learning efficiency and depth, because students work systematically toward learning independence.

Strategic integration can be used to help students make the connections between past events, contemporary issues, and their own life experiences. For example, students might make the connection between historical and current immigration events in Florida and Haiti, and their own experiences with moving to a new place.

\section{Mathematics}

In mathematics, big ideas also can reduce the burden on students with diverse learning needs to memorize information. Many students learn to solve complex math problems by memorizing various formulas and applying the correct formula to a specific problem or task. Students with diverse learning needs will have difficulty adopting this strategy because, first, the sheer number of formulas may exceed their memory skills and, second, these students may lack conceptual understanding of how to determine which formula to apply.

Frequently, however, formulas can be reduced, changed, or grouped conceptually to aid organization and retrieval. Traditionally, seven different formulas using measures of length, width, height, diameter, and radius are applied to compute the volume of seven shapes (rectangle, wedge, triangular pyramid, cylinder, rectangular pyramid, cone, and sphere). These seven formulas can be reduced to one primary formula (base times height) with two slight variations based on the shape of the object (Carnine, Jones, \& Dixon, 1994). Thus, rather than memorizing seven formulas and matching the correct one to a given shape to determine its volume, students need to learn one basic formula for volume and how to use variations of that formula to determine the volume of a given shape. In addition to simplifying the amount of information to memorize, students' conceptual understanding of volume will increase because, to calculate the volume of multiple shapes, students will have to understand why and how to apply variations on the base-times-height formula.

To be optimally effective, this big idea in mathematics has to be supported by additional instructional design principles.
Determining volume using one formula instead of seven also depends on the strategic integration of specific math concepts. Students must understand the concept of geometric area to determine the base of shapes. After the concept of area is learned, the related concept of volume can be taught in the context of base (i.e., area of the base) times height (Carnine, Jones, et al., 1994). Using volume as the big idea, conspicuous strategies are aligned closely with scaffolding. The strategy for calculating volume is to determine the base times height of a shape (with two minor variations). Mediated scaffolding will ensure that students can perform simple aspects of this strategy in isolation (e.g., calculating the area of a base) before having them attempt complex problems (e.g., calculating the volume of a shape) or problems that require the analysis of information (e.g., story problems) to arrive at the answer.

\section{Beginning Reading}

Big idea: phonological awareness. In a review of reading research, the role and relation of phonological awareness to beginning reading acquisition garnered convincing and converging evidence (Smith, Simmons \& Kameenui, 1995). Specifically, empirical evidence focused on the conclusion that beginning readers must be able to hear and manipulate sounds in words and understand the sound structure of language. Evidence derived from dozens of primary and secondary sources confirmed that children who are strong in phonological awareness usually learn to read more easily than children with delayed abilities (Juel, 1988; Smith et al., 1995; Stanovich, 1986; Torgesen, Wagner, \& Rashotte, 1994).

Moreover, Smith et al. found converging evidence indicating that phonological awareness is (a) a complex process composed of many components; (b) a reliable predictor for later reading achievement; (c) causally related to reading development; and (d) developed successfully through instruction and practice. From this robust, foundational knowledge base, we ascertained that the ability to hear and manipulate sounds in language is a big idea and essential to early reading acquisition.

In beginning reading, big ideas are the unifying curriculum activities that enable learners to translate the alphabetic code into meaningful language. The research on phonological awareness provides compelling evidence that these skills are fundamental to beginning reading and deserve considerable attention in the early reading curriculum.

Big ideas represent perhaps the largest modification or shift in thinking for publishers, developers, and teachers. In a period when teachers are forced to make instructional choices, big ideas provide guidelines about essential components of beginning reading programs. Currently, we are analyzing kindergarten and first-grade basal reading programs to iden- 
tify the quantity and quality of phonological awareness instruction with particular emphasis on big ideas, conspicuous strategies, and mediated scaffolding (Simmons et al., 1995). Preliminary findings indicate that the majority of basal programs incorporate the big idea of phonological awareness as a routine lesson component. Despite these activities, our review further suggests that design of instruction may not address the needs of students with diverse learning needs sufficiently.

Our analysis of basal reading programs indicated a tendency to identify a base activity, such as word-to-word matching or rhyming, and to use that activity across a series of lessons. In several basal reading programs the phonological awareness activity remained relatively constant and the letter-sound correspondence varied to correspond with the emphasis of the lesson. Though this consistency in curriculum design provides an anticipatory set for teachers and likely increases the predictability and usability of the materials, it likewise poses predictable limitations.

Reading research has documented that phonological awareness is a construct composed of multiple components (e.g., rhyming, blending, segmenting). These components relate differentially to reading acquisition; the processes of segmentation and blending correlate more strongly with reading acquisition than less complex processes such as sound isolation or rhyming (Yopp, 1988). The correlational nature of these data preclude definitive instructional decisions; nevertheless, a logical implication suggests that a curriculum provide beginning readers frequent opportunities to practice the phonological processes associated more highly with word reading.

Example. The example in Figure 1 is representative of the types of activities first-grade basal reading programs use to promote phonological awareness. According to the teacher's

\section{Big Idea: Phonological Awareness}

\section{Existing Example: Lesson 4 \\ Teach/Model \\ Inconspicuous Strategy: Word-to-Word Matching}

Develop phonemic awareness of $/ \mathbf{n} /$.
Tell children they will be learning about the sound they hear at the beginning of nest and the letter that stands for that sound. Display the picture side of the picture cards for $/ \mathrm{n} /$ and assorted other picture cards. Identify the pictures with children. Have them sort the pictures by the names of pictures that begin the same as nest and those that do not. Have them say the names of the pictures that begin like nest.

\section{Enhanced Example: Lesson 4 \\ Teach/Model \\ Conspicuous Strategy: Word-to-Word Matching/Sound Isolation}

Teacher Model /n/ sound. "Today you will be learning about the sound you hear at the beginning of nest. The beginning sound in nest is $/ \mathrm{n} /$. " [Display picture cards that begin with $/ \mathrm{n} /$.] "Here are some pictures that begin with $/ \mathrm{n} /$. I'll name the picture and the beginning sound. Then you name the picture: net, $/ \mathrm{n} /$; nut, /n/; needle, /n/; nine, /n/; newspaper, /n/."

Student Listen to $/ \mathrm{n} /$ and say words that begin with $/ \mathrm{n} /$.

Teacher Assist student understanding of sound isolation. "Here are other pictures that begin with $/ \mathrm{n} /$. I want you to name the picture and the beginning sound." [Display picture cards that begin with $/ \mathrm{n} /$.]

Student Isolate beginning $/ \mathrm{n} /$ sound.

Teacher Assess student understanding of sound isolation. "Here are some more pictures. Some begin with $/ \mathrm{n} /$, some begin with $/ \mathrm{h} /$, and some begin with $/ \mathrm{w} /$. When I show a picture, you name it and then say the beginning sound." [Display picture cards that begin with $/ \mathrm{n} /, \mathrm{h} /$, and $/ \mathrm{w} /$.]

Student Isolate beginning / $\mathbf{n}$ / sound and other sounds.

Teacher Assess student understanding of sound isolation. "With these pictures, I want you to name each picture. Then put the pictures that begin with $/ \mathrm{n} /$ in one pile, those that begin with $/ \mathrm{h} / \mathrm{in}$ a second pile, and those that begin with $/ \mathrm{w} /$ in a third pile" [Display Picture Cards that begin with $/ \mathrm{h} /$, $/ \mathrm{h} /$, and $/ \mathrm{w} /$.]

Student Use beginning sounds to match and discriminate words. 
guide of a specific program, the objective of the activity is to develop phonemic awareness of $/ \mathrm{n} /$. The strategy requires learners to identify the sound of the letter at the beginning of nest and compare other words to determine whether the initial sound is a match with the initial sound of the target word. In essence, the task requires learners to make a word-to-word match based on the sameness of initial sounds. This example provides multiple pictures from which students discriminate those that begin the same as nest and those that do not. The task as presented in the teacher's guide is found in Figure 1.

The existing example requires students to sort through the instructional language to discern the objective of the task: to determine that $/ \mathrm{n} /$ is the target sound. Success of this task is predicated on learners' understanding the concept beginning and their ability to extract the desired objective from only one example of the target sound in a word. The complexity of the task is increased further by requiring students to discriminate words that begin the same as nest from those that do not before they have had sufficient practice with the target sound only.

This instruction may be sufficient for some learners in first grade; however, an increasing number of children require more than is specified currently in instructional manuals. The following recommendations may seem commonplace and straightforward; however, research indicates that these types of recommended modifications are not characteristic of basal reading programs.

We propose that the potential problems in the activity can be mediated by attending to the curriculum design principles of conspicuous strategies and mediated scaffolding. Conspicuous strategies in beginning reading are the steps that lead to effective and efficient word recognition. In phonological awareness, they are the steps a reader takes to recognize and figure out the sound structure of a word. Unfortunately, many learners do not intuit or figure out the processes of blending or segmenting sounds in words until much time has passed and many opportunities for learning have been exhausted. It is the process of making explicit the steps of manipulating the sounds in your head or figuring out a word that has to be conspicuous for students.

To rectify potential learning obstacles, we first recommend that the instructional strategy be more conspicuous. Through a sequence of teaching events and teacher actions, requirements of the task can be made more explicit. This is achieved by modeling the intended outcomes of the task as illustrated in the enhanced example in Figure 1. In this example, the teacher identifies the target sound and then names multiple pictures, all which begin with the target sound. Through explicit attention to the target sound and the use of multiple examples, students learn the commonalities in the target words and the task expectations.
In addition to conspicuous strategies, the enhanced example incorporates several forms of mediated scaffolding. First, teachers model the process of matching initial sounds of words. Next, initial learning is supported by focusing first on words with $/ \mathrm{n} /$. Before students are asked to discriminate pictures that begin with $/ \mathrm{n} /$ from those that do not, they practice identifying the initial sound in words that begin with $/ \mathrm{n} /$. Only after students have had multiple opportunities to hear the critical feature of words are discrimination words (e.g., horse, window) introduced.

An additional enhancement strategically structures the difficulty of the task by selecting words from which children discriminate. By limiting the discrimination tasks to words containing sounds that children know (e.g., $w$ and $h$ ), have had sufficient practice with, and are not easily confused with the target sound $n$, learners are more likely to be successful.

\section{Written Expression}

Big idea: narrative text structure. In reading and writing, text structure represents an example of a big idea. The underlying text structure in narrative prose is story grammar. Story grammar refers to a set of rules and elements typically occurring in a story. Research provides evidence that instruction in story grammar enhances comprehension of stories for normally achieving and low-achieving students and for students with learning disabilities (Carnine \& Kinder, 1985; Dimino, Gersten, Carnine, \& Blake, 1990). Research also supports strategy instruction in story grammar to improve narrative composition skills for students with learning disabilities (Graham, \& Harris, 1989). Building on the work of Dimino et al. (1990), Graves, Montague, and Wong (1990), and Nezworski, Stein, and Trabasso (1982), we developed an integrated strategy that relies on story grammar elements: setting, main character, additional characters, character development (including inferred descriptions), problem, attempts to solve, resolution (or failure to resolve), conclusion, and theme.

Strategic integration: reading and writing. Reading and writing taught together seem to engage learners in a greater variety of reasoning operations than when taught separately. In a comprehensive examination of studies, including those with large and small sample sizes and varying subject ages, Tierney and Shanahan (1991) found consistent support for integrated instruction of reading and writing. Integrated reading and writing seemed to enhance thinking operations and learning of key concepts. In a 3-year study with 400 students in grades 9-11, Langer and Applebee (1987) concluded that essay writing following reading prompted students to focus more deeply on specific sections of text and prompted more 
written comments representing a greater variety of reasoning operations than note-taking or study guide questions. Reading followed by a writing exercise resulted in significantly more learning than did reading without some form of writing task (Langer \& Applebee, 1987).

Besides enhancing thinking and comprehension, integrated reading and writing also may improve writing. Shanahan and Lomax (1986) found the influence of reading-to-write stronger than the influence of writing-to-read. Noyce and Christie (1985) concluded further that integrated instruction in reading and writing in complex syntactic structures produced greater gains in reading and writing than instruction in writing only. Likewise, Englert, Raphael, Anderson, Anthony, and Stevens (1991) found achievement gains by integrating the writing process and role of text structure knowledge in teaching writing strategies to students with and without learning disabilities.

Conspicuous strategy: writing process. Several researchers (e.g., Graham and Harris, Seidenberg, Isaacson, and Englert) have addressed the effects of strategy instruction in writing. Research studies investigating writing strategy instruction for students with learning disabilities have examined the benefits of specific instructional components and have documented support for the teacher (a) explicitly introducing, explaining, and describing writing strategies, (b) modeling the strategy through think-alouds, (c) providing opportunities for students to interact and collaborate with the teacher and each other, (d) providing scaffolds and (e) training students in self-instructional strategies and self-monitoring. In particular, Englert et al. (1991) investigated teaching a writing process to students with and without learning disabilities using a writing strategy that consists of plan, organize, write, edit, and revise and known by the acronym POWER.

Mediated scaffolding. Phases of individual scaffolding occurred in Englert's investigations of effective writing instruction. First, teachers introduced a writing strategy and think-sheets by modeling and thinking aloud. In the next phase, teachers and students jointly applied writing strategies. Finally, teachers provided guidance and opportunities for students to practice writing on topics of their own choice (Englert et al., 1991).

Another dimension of scaffolding is content presentation, the selection and sequence of content to enable students to learn and be successful. Dimino et al. (1990) scaffolded content by initially using shorter, less complex stories to teach easier, more obvious story grammar elements (character, problem, attempts, and resolution) before teaching more difficult story grammar elements (character clues based on in- ferences and theme). As students became more proficient at identifying story grammar elements, story length and complexity increased.

A third dimension of scaffolding, material prompts, provides external supports (procedural facilitation) for students (Scardamalia \& Bereiter, 1986). In writing instruction, material prompts cue strategy use and help less experienced students emulate mature writers' performance (Scardamalia \& Bereiter, 1986). Research studies have investigated a range of material prompts including think-sheets to activate planning, organizing, drafting, editing, and revising note sheets (Englert et al., 1991), for recording story grammar elements (Dimino et al., 1990), and story grammar cue cards, verbal reminders for character development, and metacognitive check-off procedures (Graves et al., 1990).

In task scaffolding, a fourth dimension of scaffolding, tasks gradually increase in difficulty. An example of scaffolded tasks is found in the work of Graham and Harris (1989). Students identified story grammar elements in stories, generated story grammar elements while looking at a picture, generated self-instruction statements to generate story parts, and practiced story writing strategies before composing stories independently. Another example of scaffolded tasks is providing students opportunities to write rough drafts and edit them, then write revised copies. This helps prevent students from feeling overwhelmed by attempting to write perfect papers. Students focus first on communicating ideas, then on mechanics.

Judicious review. Reading and writing instruction requires an appropriate review schedule to reinforce and maintain knowledge and use of information. Based on review research, effective practice depends upon (a) time between repetitions, (b) frequency of repetitions, and (c) form of repetition (Dempster, 1991). Effective review also is cumulative, integrating skills and strategies and providing review opportunities over an extended time (Dixon, Carnine, \& Kameenui, 1992). As skills and strategies for improving reading comprehension and writing are introduced, a firming cycle should be used. A firming cycle is the "repeated presentation of new and/or problematic tasks both throughout and at the end of a lesson to assure that students are firm on the information" (Kameenui \& Simmons, 1990, p. 235).

\section{THE EFFECTS OF EDUCATIONAL TOOLS: BEYOND THE INSTRUCTIONAL VENEER}

In 1985, Gickling and Thompson coined the term curriculum casualties to refer to the interaction of curricula that move too fast in relation to learners' existing skills. They fur- 
ther noted that the cumulative effect of poorly designed curricula and instruction result is a failure cycle wherein learners become perpetually and increasingly discrepant from their peers. Dixon and Carnine (1993) reinforced curriculum effects proposing that "poorly designed instruction can have an effect on students that is less than poor learning: students can learn misconceptions that become stubborn impediments to all future remediation efforts" (p. 18).

A common tenet of instructional design is the power of the negative example (Engelmann \& Carnine, 1982). Dixon and Carnine used the negative example skillfully to communicate what a curriculum would look like if it were designed intentionally to be difficult for students. (What would be the negative features of a curriculum for students with diverse learning needs?) Their analysis focused on mathematics; however, the principles generalize to other content areas. A curriculum designed intentionally to be difficult for students with diverse learning needs would:

- Teach very little thoroughly

- Avoid opportunities to work on the "hot spots" where many students predictably fail

- Avoid linking symbolic representations with concrete manipulation

- Encourage children to infer strategies

- Focus on rote acquisition

- Teach a topic or content and drop it, failing to give students the opportunity to apply content realistically.

Additional features we would add to Carnine and Dixon's list of "criteria for poorly designed curricula" are the following:

- Provide few explicit examples of how to perform a task

- Assume that learners have adequate background information and know when and how to use it

- Leave it entirely up to the learner to make the connections between information

- Allocate equal amounts of time to all instructional objectives

- Assume that instructional time is unlimited.

Currently, we have no easy or fully specified answers for how to optimize academic learning for the increasingly large number of children who fail to benefit adequately from current educational practices and tools. Instructional practices and educational curricula, however, currently are under scrutiny as states seek a cause and a solution to unprecedented rates of failure (Diegmueller, 1995). As proposed in this article and heralded historically by research on curriculum design, students who fail to respond to traditional instruction may require an intensity and an integrity of instruc- tion different from past and present practices and educational tools. The diverse needs of children in today's schools are not likely to be resolved by adding instructional veneer to existing educational tools. Practitioners, administrators, educational researchers, publishers, developers, and personnel who prepare general and special educators alike must take seriously the role that educational tools play in learning and recognize the scientific body of knowledge available to guide curriculum design.

\section{REFERENCES}

Armbruster, B., \& Ostertag, J. (1993). Questions in elementary science and social studies textbooks. In B. K. Britton, A. Woodward, \& M. Binkley (Eds.), Learning from textbooks: Theory and practice (pp. 69-94). Hillsdale, NJ: Erlbaum.

Baker, J., \& Zigmond, N. (1990). Are regular education classes equipped to accommodate students with learning disabilities? Exceptional Children, 56, 515-526.

Baker, S., Simmons, D., \& Kameenui, E. (1994). Making information more memorable for students with learning disabilities. Learning Disabilities Forum, 19, 14-18.

Bateman, B. (in press). Legal research on what constitutes "specially designed instruction" and quality technology, media, and materials for students with disabilities. (Tech. Rep.). Eugene: Oregon: University of Oregon, National Center to Improve the Tools of Educators.

Beck, I. L., McKeown, M. G., \& Gromoll, E. W. (1989). Learning from social studies texts. Cognition \& Instruction, 12, 118-132.

Brophy, J. (1990). Teaching social studies for understanding and higher-order applications. Elementary School Journal, 90, 353-417.

Carnine, D. (1993, December 8). Facts, not fads. Education Week, p. 40.

Carnine, D. (1994). Introduction to the mini-series: Educational tools for diverse learners. School Psychology Review, 23, 341-350.

Carnine, D., Jones, E. D., \& Dixon, B. (1994). Mathematics: Educational tools for diverse learners. School Psychology Review, 23, 406-427.

Carnine D., \& Kinder, D. (1985). Teaching low-performing students to apply generative and schema strategies to narrative and expository material. Remedial \& Special Education, 6, 20-30.

Carnine, D., Miller, S., Bean, R., \& Zigmond, N. (1994). Social studies: Educational tools for diverse learners. School Psychology Review, 23, 428-441

Carroll, J. B. (1963). A model of school learning. Teachers College Record, 64, 723-733.

Dempster, F. N. (1991, April). Synthesis of research on reviews and tests. Educational Leadership, 48, 71-76.

Diegmueller, K. (1995, June 14). California plotting new tack on language arts. Education Week, p. 1.

Dimino, J., Gersten, R., Carnine, D., \& Blake, G. (1990). Story grammar: An approach for promoting at-risk secondary stu- 
dents' comprehension of literature. Elementary School Journal, 91, 19-32.

Dixon, B., \& Carnine, D. (1993). The hazards of poorly designed instructional tools. Learning Disabilities Forum, 18(3), 18-22.

Dixon, R., Carnine, D. W., \& Kameenui, E. J. (1992). Curriculum guidelines for diverse learners. Monograph for National Center to Improve the Tools of Educators. Eugene: University of Oregon.

Engelmann, S., \& Carnine, D. W. (1982). Theory of instruction: Principles and applications. New York: Irvington.

Englert, C. S., Raphael, T. E., Anderson, L. M., Anthony, H. M., \& Stevens, D. D. (1991). Making strategies and self-talk visible: Writing instruction in regular and special education classrooms. American Educational Research Journal, 2, 337-372.

Frymier, J., Barber, L., Carriedo, R., Denton, W., Gansneder, B., Johnson-Lewis, S., \& Robertson, N. (1992). Growing up is risky business and schools are not to blame. Bloomington, IN: Phi Delta Kappa.

Fuchs, D., \& Fuchs., L. (1994). Classwide curriculum-based measurement: Helping general educators meet the challenge of student diversity. Exceptional Children, 60, 518-537.

Gickling, E., \& Thompson, V. (1985). A personal view of curriculum-based assessment. Exceptional Children, 52, 219-232.

Graham, S., \& Harris, K. R. (1989). A components analysis of cognitive strategy instruction: Effects on learning disabled students' compositions and self-efficacy. Journal of Educational Psychology, 81, 356-361.

Graves, A., Montague, M., \& Wong, Y. (1990). The effects of procedural facilitation on the story composition of learning disabled students. Learning Disabilities Research, 5, 88-93.

Hoffman, J. V., McCarthey, S., Abbot, C., Corman, L., Dressman, M., Elliott, B., Matherne, D., \& Stahle, D. (1994). So what's new in the new basals? A focus on first grade. Journal of Reading Behavior, 26, 47-73.

International math and science study finds US covers more in less depth. (1994, June 24). Education Week, p. 10.

Juel, C. (1988). Learning to read and write: A longitudinal study of 54 children from first through fourth grades. Journal of Educational Psychology, 80, 437-447.

Kameenui, E. J. (1993). Diverse learners and the tyranny of time: Don't fix blame; fix the leaky roof. Reading Teacher, 46, 376-383.

Kameenui, E. J., Carnine, D. W., \& Dixon R. C. (In press). Effective teaching strategies that accommodate diverse learners. In E. J. Kameenui (Ed.), Effective teaching strategies that accommodate diverse learners. Columbus, $\mathrm{OH}$ : Merrill.

Kameenui, E. J., \& Simmons, D.C. (1990). Designing instructional strategies: The prevention of academic learning problems. Columbus, OH: Merrill.

Kauffman, J. M. (1994). Places of change: Special education's power and identity in an era of educational reform. Journal of Learning Disabilities, 27, 610-618.

Kinder, D., \& Bursuck, W. (1991). The search for a unified social studies curriculum: Does history really repeat itself? Journal of Learning Disabilities, 24, 270-275.
Langer, J., \& Applebee, A. (1986). Reading and writing instruction: Toward a theory of teaching and learning. In E. Rothkopf (Ed.), Review of research in education (Vol. 13) (pp. 171-194). Washington, DC: American Educational Research Association.

Longstreet, W. S., \& Shane, H.G. (1993). Curriculum for a new millennium. Boston: Allyn \& Bacon.

Mayer, R., Sims, V., \& Tajika, H. (1995). A comparison of how textbooks teach mathematical problem solving in Japan and the United States. American Educational Research Journal, 32, $443-460$.

McLeskey, J., \& Pacchiano, D. (1994). Mainstreaming students with learning disabilities: Are we making progress? Exceptional Children, 60, 508-517.

Mosenthal, P. (1982). Designing training programs for learning disabled children: An ideological perspective. Topics in Learning and Learning Disabilities, 2, 97-107.

Nezworski, T., Stein, N. L., \& Trabasso, T. (1982). Story structure versus content in children's recall. Journal of Verbal Learning \& Verbal Behavior, 21, 196-206.

Nolet, V., \& Tindal, G. (1994). Instruction and learning in middle school science classes: Implications for students with disabilities. The Journal of Special Education, 28, 166-187.

Noyce, R. M., \& Christie, J. F. (1985). Effects of an integrated approach to grammar instruction on third graders' reading and writing. Elementary School Journal, 84, 63-69.

Porter, A. C. (1989, June-July). A curriculum out of balance: The case of elementary school mathematics. Educational Researcher, 18(5), 9-15.

Reading scores for high school seniors show drop. (1995, April). Register Guard, p. A7.

Scardamalia, M., \& Bereiter, C. (1986). Research on written composition. In M. C. Wittrock (Ed.), Handbook of research on education (3d ed., pp. 778-803). New York: Macmillan.

Shanahan, T., \& Lomax, R. G. (1986). An analysis and comparison of theoretical models of the reading-writing relationship. Journal of Educational Psychology, 78, 116-123.

Simmons, D. C., Gleason, M. M., Smith, S. B., Baker, S. K., Sprick, M., Thomas, C., Gunn, B., Chard, D., Plasencia-Peinado J., Peinado, R., \& Kameenui, E. J. (1995, April). Applications of phonological awareness research in basal reading programs: Evidence and implications for students with reading disabilities. Paper presented at meeting of American Educational Research Association, San Francisco.

Simmons, D., Kameenui, E. J., Dickson, S., Chard, D., Gunn, B., \& Baker, S. Integrating narrative reading and writing instruction for all learners. (1994). Yearbook of the National Reading Council, 43, 572-582.

Smith, P. L. \& Ragan, T. L. (1993). Instructional design. New York: Merrill.

Smith, S. B., Simmons, D. C., \& Kameenui, E. J. (1995). Synthesis of research on phonological awareness: Principles and implications for reading acquisition (Tech. Rep. No. 21). Eugene: University of Oregon, National Center to Improve the Tools of Educators. 
Stanovich, K., E. (1986). Matthew effects in reading: Some consequences of individual differences in the acquisition of literacy. Reading Research Quarterly, 21, 360-406.

Tennyson, R., \& Christensen, D. L. (1986, April). Memory theory and design of intelligent learning systems. Paper presented at meeting of American Educational Research Association, San Francisco.

Tierney, R. J., \& Shanahan, T. (1991). Research on the reading-writing relationship: Interactions, transactions, and outcomes. In R. Barr, M. Kamil, P. B. Mosenthal, \& P. D. Pearson (Eds.), Handbook of reading research (Vol. 2), (pp. 246-280). New York: Longman.

Torgesen, J., Wagner, \& Rashotte, C. (1994). Longitudinal studies of phonological processing and reading. Journal of Learning Disabilities, 27, 276-286.

U. S. Department of Education (1994). Sixteenth annual report to Congress on the implementation of the Individuals with Disabilities Education Act. Washington, DC: Government Printing Office.

Worrall, R. S., \& Carnine, D. (1994, March). Lack of professional support undermines teachers and reform-A contrasting per- spective from health and engineering. Unpublished manuscript, National Center to Improve the Tools of Educators, College of Education, University of Oregon, Eugene.

Yopp, H. K. (1988). The validity and reliability of phonemic awareness tests. Reading Research Quarterly, 23, 159-177.

Zigmond, N., Jenkins, J., Fuchs, L. S., Deno, S., Fuchs, D., Baker, J. N., Jenkins, L., \& Couthino, M. (1995, March). Special education in restructured schools: Findings from three multi-year studies. Phi Delta Kappan, 76(7), 531-540.

We would like to acknowledge Scott Baker, Doug Carnine, David Chard, Shirley Dickson, Bob Dixon, Zig Engelmann, and Sylvia Smith for the concepts, writings, and research that contributed significantly to the development of this article.

Preparation of this article was supported in part by The National Center to Improve the Tools of Educators (H180M10006) funded by the U.S. Department of Education, Office of Special Education Programs. 